\title{
Thyroid dysfunction in children and adolescence: Experience of a tertiary care centre in Kerala
}

\author{
Lakshminarayana Gopaliah $\mathbf{R}^{1}$, Sheetal Lakshminarayana $G^{2}$, Nidhish P Sadanandan ${ }^{3}$, Pramod Mundekkat ${ }^{4}$ \\ ${ }^{1}$ Dr. Lakshminarayana Gopaliah R, MBBS, DNB (General Medicine), DNB (Nephrology), MNAMS, \\ PGDHR, Consultant Nephrologist, Department of Nephrology, EMS Memorial Cooperative Hospital and Research \\ Centre, Perinthalmanna, Malappuram, Kerala, India. ${ }^{2}$ Dr. Sheetal Lakshminarayana G, MBBS, MD \\ (Physiology), DNB (Physiology), MHA, Associate Professor, Department of Physiology, MES Medical \\ College, Perinthalmanna, Malappuram, Kerala, India. ${ }^{3}$ Mr. Nidhish P Sadanandan, MSc (Physiology), Tutor, \\ Department of Physiology, Amrita Institute of Medical Sciences and Research Centre, AIMS Ponekkara PO, Kochi, \\ Kerala, India, ${ }^{4} \mathrm{Mr}$. Pramod Mundekkat, In charge, Electronic Medical Records, EMS Memorial Cooperative \\ Hospital and Research Centre, Perintha, Imanna, Malappuram, Kerala, India.
}

Address for Correspondence: Dr. Lakshminarayana GR, Consultant Nephrologist, Department of Nephrology, EMS Memorial Cooperative Hospital and Research Centre, Perinthalmanna, Malappuram, Kerala, India.

E-mail: drlng23@gmail.com.

\begin{abstract}
Background: There is limited data regarding the prevalence of thyroid disorders in children and adolescents from India. Methods: All subjects aged 1-19 years, who underwent estimation of thyroid function tests (TFTs) at the EMS Memorial Cooperative Hospital and Research Centre, Perinthalmanna (2009-2013) were included in the study. Results: A total of 784 subjects (males-336, females-448), aged between 1-19 (Mean 11.12, SD-6.23) years, who underwent estimation of TFTs were studied. The prevalence rate of all thyroid function abnormalities was $9.18 \%$. The thyroid function disorders were more common (10.89\%) in adolescents (14-19 years) than children (1-13 years) (7.82\%) and in females (12.05\%) than males (5.36\%) in both age groups. The prevalence rates of subclinical hypothyroidism ( $\mathrm{SCH}$ ), overt hypothyroidism $(\mathrm{OH})$ and hyperthyroidism were 4.08\%, 3.05\% and 2.04\% respectively. Conclusions: The thyroid function abnormalities are common in children and adolescents affecting about $\sim 9 \%$ in study population. The SCH was the commonest thyroid function disorder, followed by $\mathrm{OH}$ and hyperthyroidism with female: male ratios of 2.5:1, 2.43:1 and 7:1 respectively. Majority of cases $\mathrm{OH}$ were of primary hypothyroidism. The $\mathrm{SCH}$ and hyperthyroidism were more prevalent in the adolescents than children; however, $\mathrm{OH}$ was more common in children than adolescents.
\end{abstract}

Key-words: Hypothyroidism, Hyperthyroidism, Subclinical Hypothyroidism,

\section{Introduction}

The thyroid function disorders are very common in the world, however, there is limited data regarding them in children and adolescents. The reported prevalence rates vary from 0.11 to $0.12 \%$ in two studies [1,2] to $3.7 \%$ in another study [3]. Prevalence of subclinical hypothyroidism $(\mathrm{SCH})$ was found in $<2 \%$ of study population; in an Indian study [4]. The evolution rate of $\mathrm{SCH}$ to overt hypothyroidism $(\mathrm{OH})$ on follow-up ranges from $0-28.8 \%$ in another study[5]. Most cases of childhood hypothyroidism are sporadic and 10-15\% disorders are caused by inherited defects. $[6,7,8]$.

Manuscript received: $25^{\text {th }}$ Nov 2015

Reviewed: $16^{\text {th }}$ Dec 2015

Author Corrected; 29th Dec 2015

Accepted for Publication: $4^{\text {th }}$ Jan 2016
Chronic lymphocytic thyroiditis is the most frequent etiology for hypothyroidism in children after neonatal period with common age of onset during in adolescence. [6, 7, 8]. The clinical presentation of hypothyroidism varies widely and the prognosis of depends on age of onset of disease; early diagnosis and levothyroxine supplementation has a better result on linear growth and mental development. $[6,7,8]$. There is limited data regarding prevalence of thyroid disorders in children and adolescents from India. In one of the study prevalence rates of $\mathrm{SCH}$ and $\mathrm{OH}$ was $6.1 \%$ and $0.4 \%$ respectively among study population of $\sim 39,000$ children [9]. There is no data regarding the prevalence rates of thyroid disorders in children and adolescents from Kerala. 


\section{Material and Methods}

Study design and subjects: This was a retrospective study conducted at EMS Memorial Cooperative Hospital and Research Centre, Perinthalmanna, Malappuram, Kerala; a tertiary care, referral centre in northern Kerala. All subjects aged 1-19 years, who underwent estimation of thyroid function tests (TFTs) on their first outpatient visit from September 2009 to December 2013, were included in the study. The subjects were categorised into two groups based on age (1-13 years-children, 14-19 years-adolescents) and gender for analysis. Aims of the study were to measure the overall prevalence of thyroid disorders in children and adolescents, and to analyse their differences based on age and gender.

Thyroid function test estimation, diagnosis and statistics: The triiodothyronine (T3), tetraiodothyronine (T4) and thyroid stimulating hormone (TSH) were analysed by electrochemiluminescence assay (CobasRoche Elecys Core immunoassay system - Roche Diagnostics, Mannheim, GmbH). Normal range for T4, T3 and TSH were 5.1-14.1 $\mu \mathrm{g} / \mathrm{dL}, 60-180 \mathrm{ng} / \mathrm{dL}$ and 0.35 to $5.5 \mu \mathrm{IU} / \mathrm{mL}$ respectively, with intra assay and inter assay coefficient of variation (CV) being less than $7 \%$ for all three parameters. There was no specified normal range for the local population; hence, the TFTs were classified as abnormal if values were beyond normal limits of according to TFT kit. The TFT reports above the laboratory reference ranges are considered abnormal by most Pediatricians.

In our study subjects were classified using following definitions:

Primary hypothyroidism: TSH $>5.5 \mu \mathrm{IU} / \mathrm{mL}$ and T4 $<5.1 \mu \mathrm{g} / \mathrm{dL}$ or T3 $<60 \mathrm{ng} / \mathrm{dL}$.

Subclinical hypothyroidism: $\mathrm{TSH}>5.50 \mu \mathrm{IU} / \mathrm{mL}$ and normal T4, normal T3.

Secondary hypothyroidism: $\mathrm{T} 4<5.1 \mu \mathrm{g} / \mathrm{dL}$ or $\mathrm{T} 3<60$ $\mathrm{ng} / \mathrm{dL}$ and a TSH level that is not appropriately elevated.

Hyperthyroidism: TSH $<0.35 \mu \mathrm{IU} / \mathrm{mL}$ and T3 $>180$ $\mathrm{ng} / \mathrm{dL}$ or $\mathrm{T} 4>14.1 \mu \mathrm{g} / \mathrm{dL}$.

Subclinical hyperthyroidism: TSH $<0.35 \mu \mathrm{IU} / \mathrm{mL}$ and normal T3, normal T4.

Secondary hyperthyroidism: $\mathrm{T} 3>180 \mathrm{ng} / \mathrm{dL}$ or $\mathrm{T} 4$ $>14.1 \mathrm{ng} / \mathrm{dL}$ and a TSH level that is not appropriately supressed.

Statistical analysis was performed using SPSS (Version 17) for Windows. The quantitative variables (age, TSH, $\mathrm{T} 3$, T4) have been described as mean $\pm \mathrm{SD}$ and range. The prevalence rates of thyroid disorders were summarized as counts and percentages. A Chi-square test was used to assess the trends in the prevalence of hypothyroidism, $\mathrm{SCH}$ and hyperthyroidism among different age groups and gender categories. A p value of $<0.05$ was taken as significant.

\section{Observations}

A total of 784 subjects (males-336, females-448), aged between 1-19 (Mean 11.12, SD-6.23) years, who underwent estimation of TFTs from 2009 to 2013 were included in the study [Table 1]. The majority (85\%) of the study population was reportedly consuming iodized salt. The range, mean and standard deviation of age, TSH, T3, and T4 are summarised according to age groups in table 1. Thyroid function abnormalities were present in $9.18 \%$ of subjects [table 2]. The prevalence rate of thyroid function abnormalities was higher in females $(12.05 \%)$ than males $(5.36 \%)$ [Table 2 ]. Thyroid function abnormalities were more prevalent in adolescents $(10.89 \%)$ than children $(7.82 \%)$ [Table 3 ].

Table 1: Descriptive data of T3, T4, and TSH levels according to age groups

\begin{tabular}{|l|l|l|l|}
\hline \multirow{4}{*}{ Parameter } & \multicolumn{2}{l|}{ Age group } & $1-13$ years \\
\cline { 2 - 4 } & $\begin{array}{l}\text { All subjects } \\
(\mathrm{n}=784) \\
\text { Mean } \pm \text { SD (Range) }\end{array}$ & $\begin{array}{l}\text { (n= 435) } \\
\text { Mean } \pm \text { SD (Range) }\end{array}$ & $\begin{array}{l}\text { 14-19 years } \\
(\mathrm{n}=349) \\
\text { Mean } \pm \text { SD (Range) }\end{array}$ \\
\hline Age & $11.12 \pm 6.23$ & $6.48 \pm 4.38$ & $16.91 \pm 1.72$ \\
\hline \multirow{2}{*}{$\mathrm{T} 3 \mathrm{ng} / \mathrm{dL}$} & $128.71 \pm 31.07$ & $133.37 \pm 30.74$ & $122.91 \pm 30.52$ \\
& $19.53-348.20$ & $20-251$ & $26.45-348.20$ \\
\hline \multirow{2}{*}{$\mathrm{T} 4 \mu \mathrm{g} / \mathrm{dL}$} & $9.25 \pm 2.37$ & $9.45 \pm 2.47$ & $0.53 \pm 21.19$ \\
& $0.51-21.19$ & $0.51-17.49$ & $0.43-24.86$ \\
\hline \multirow{2}{*}{$\mathrm{TSH} \mu \mathrm{IU} / \mathrm{mL}$} & $4.56 \pm 13.48$ & $4.64 \pm 13.66$ & $4.46 \pm 13.26$ \\
& $0.005-100$ & $0.02-100$ & $0.00-100$ \\
\hline
\end{tabular}


Table 2: Prevalence rate of thyroid dysfunction and its variation according to gender.

\begin{tabular}{|l|l|l|l|l|}
\hline \multirow{2}{*}{ Parameter } & \multicolumn{2}{|l|}{ Age 1-19 Years } & $\begin{array}{l}\text { Chi square test } \\
\text { (prevalence in males } \\
\text { vs females) } \\
\text { p value }\end{array}$ \\
\cline { 2 - 5 } & $\begin{array}{l}\text { All Subjects (784) } \\
\mathrm{n}(\%)\end{array}$ & $\begin{array}{l}\mathrm{M}(336) \\
\mathrm{n}(\%)\end{array}$ & $\begin{array}{l}\mathrm{F}(448) \\
\mathrm{n}(\%)\end{array}$ & 6.09 \\
\hline Hypothyroidism (primary) & $23(2.93)$ & $17(3.79)$ & $0.78)$ & 0.24 \\
\hline Hypothyroidism (secondary) & $1(0.12)$ & $9(2.68)$ & $23(5.13)$ & 0.08 \\
\hline Subclinical Hypothyroidism & $32(4.08)$ & $2(0.59)$ & $14(3.12)$ & 0.01 \\
\hline Hyperthyroidism (primary) & $16(2.04)$ & 0 & 0 & \\
\hline Hyperthyroidism (secondary) & 0 & 0 & 0 & \\
\hline Subclinical Hyperthyroidism & 0 & $18(5.36)$ & $54(12.05)$ & 0.001 \\
\hline $\begin{array}{l}\text { Total subjects with thyroid } \\
\text { dysfunction }\end{array}$ & $72(9.18)$ & & & \\
\hline
\end{tabular}

Table 3: Prevalence rate of thyroid dysfunction and its variation according to age.

\begin{tabular}{|c|c|c|c|c|}
\hline \multirow[b]{2}{*}{ Parameter } & \multicolumn{3}{|c|}{ Age group (Years) } & \multirow{2}{*}{$\begin{array}{l}\text { Chi square test } \\
\text { (prevalence in males } \\
\text { vs females) } \\
\text { p value }\end{array}$} \\
\hline & $\begin{array}{l}\text { All subjects } \\
(784) \\
\text { n (\%) }\end{array}$ & $\begin{array}{l}1-13 \\
(435) \\
\text { n (\%) }\end{array}$ & $\begin{array}{l}14-19 \\
(349) \\
\text { n (\%) }\end{array}$ & \\
\hline Hypothyroidism (primary) & $23(2.93)$ & $13(2.98)$ & $10(2.86)$ & 0.91 \\
\hline Hypothyroidism (secondary) & $1(0.12)$ & $1(0.23)$ & 0 & 0.37 \\
\hline Subclinical Hypothyroidism & $32(4.08)$ & $12(2.76)$ & $20(5.73)$ & 0.03 \\
\hline Hyperthyroidism (primary) & $16(2.04)$ & $8(1.84)$ & $8(2.29)$ & 0.65 \\
\hline Hyperthyroidism (secondary) & 0 & 0 & 0 & \\
\hline Subclinical Hyperthyroidism & 0 & 0 & 0 & \\
\hline Total subjects with thyroid dysfunction & $72(9.18)$ & $34(7.82)$ & $38(10.89)$ & 0.13 \\
\hline
\end{tabular}

Subclinical hypothyroidism: Subclinical hypothyroidism ( $\mathrm{SCH})$ was the commonest of the thyroid function abnormalities; observed in $4.08 \%(n-32)$ of subjects; affecting females $(5.13 \%)$ more than males $(2.68 \%)$ [Table 2]. The prevalence rate of SCH was higher in the adolescents $(5.73 \%)$ than children $(2.76 \%)$ [Table 3]. The adolescent females were the most affected off all with a prevalence rate of $7.39 \%$ [Table $4 \& 5$ ].

Table 4: Prevalence rate of thyroid dysfunction in according to gender in age group of 1-13 years

\begin{tabular}{|c|c|c|c|c|}
\hline \multirow[b]{2}{*}{ Parameter } & \multicolumn{3}{|c|}{ Age group of 1-13 Years } & \multirow{2}{*}{$\begin{array}{l}\text { Chi square test } \\
\text { (prevalence in males vs } \\
\text { females) } \\
\text { p value }\end{array}$} \\
\hline & $\begin{array}{l}\text { All subjects } \\
(435) \\
\text { n }(\%)\end{array}$ & $\begin{array}{l}\text { Males } \\
(216) \\
\mathrm{n}(\%)\end{array}$ & $\begin{array}{l}\text { Females } \\
(219) \\
\mathrm{n}(\%)\end{array}$ & \\
\hline Hypothyroidism (primary) & $13(2.98)$ & $5(2.31)$ & $8(3.65)$ & 0.61 \\
\hline Hypothyroidism (secondary) & $1(0.23)$ & $1(0.46)$ & 0 & 0.13 \\
\hline Subclinical Hypothyroidism & $12(2.76)$ & $6(2.78)$ & $6(2.74)$ & 0.98 \\
\hline Hyperthyroidism (primary) & $8(1.84)$ & $1(0.46)$ & $7(3.20)$ & 0.03 \\
\hline Hyperthyroidism (secondary) & 0 & 0 & 0 & \\
\hline Subclinical Hyperthyroidism & 0 & 0 & 0 & \\
\hline Total subjects with thyroid dysfunction & $34(7.82)$ & $13(6.01)$ & $21(9.59)$ & 0.16 \\
\hline
\end{tabular}


Table 5: Prevalence rate of thyroid dysfunction in according to gender in age group of 14-19 years

\begin{tabular}{|c|c|c|c|c|}
\hline \multirow[b]{2}{*}{ Parameter } & \multicolumn{3}{|c|}{ Age group of 14-19 Years } & \multirow{2}{*}{$\begin{array}{l}\text { Chi square test } \\
\text { (Males vs females) } \\
\text { p value }\end{array}$} \\
\hline & $\begin{array}{l}\text { All subjects } \\
(349) \\
\text { n (\%) }\end{array}$ & $\begin{array}{l}\text { Males } \\
(119) \\
\mathrm{n}(\%) \\
\end{array}$ & $\begin{array}{l}\text { Females } \\
(230) \\
\mathrm{n}(\%) \\
\end{array}$ & \\
\hline Hypothyroidism (primary) & $10(2.86)$ & $1(0.84)$ & $9(3.91)$ & 0.10 \\
\hline Hypothyroidism (secondary) & 0 & 0 & 0 & \\
\hline Subclinical Hypothyroidism & $20(5.73)$ & $3(2.25)$ & $17(7.39)$ & 0.06 \\
\hline Hyperthyroidism (primary) & $8(2.29)$ & $1(0.84)$ & $7(3.04)$ & 0.19 \\
\hline Hyperthyroidism (secondary) & 0 & 0 & 0 & \\
\hline Subclinical Hyperthyroidism & 0 & 0 & 0 & \\
\hline $\begin{array}{l}\text { Total subjects with thyroid } \\
\text { dysfunction }\end{array}$ & $38(10.89)$ & $5(4.2)$ & $33(14.34)$ & 0.003 \\
\hline
\end{tabular}

Overt Hypothyroidism: Overt hypothyroidism $(\mathrm{OH})$ was the second commonest of the thyroid function abnormalities; observed in $3.05 \%(n-24)$ of subjects; affecting females $(3.79 \%)$ more than males $(2.08 \%)$ [Table 2]. Majority of cases $\mathrm{OH}$ were of primary hypothyroidism $(95.8 \%, 23$ out of 24) [Table 2]. The prevalence rate of hypothyroidism was higher in females than males; both in adolescents and children [Table 4, 5].

Hyperthyroidism: The hyperthyroidism was observed in $2.04 \%(n-16)$ of subjects [Table 2]. The hyperthyroidism was more prevalent in females $(3.12 \%)$ than males $(0.59 \%)$ [Table 2]. The prevalence rate of hyperthyroidism was higher in adolescents $(2.29 \%)$ than children (1.84\%) [Table 3] and in both age groups females were more affected than males [Table 4 \& 5].

\section{Discussion}

In our study thyroid function abnormalities were noted in $9.18 \%$ of children and adolescents. In one of the population based Indian studies almost $12 \%$ of children aged 5-16 years were found to have elevated TSH reports above reference range according to kit manufacturer [10].

In another older study from America (1965-1968); 3.7 $\%$ of children (11-18 years) were found to have thyroid function abnormalities [3]. Although; prevalence of thyroid function disorders in children and adolescents is lesser than adults (19.6\%) [12], screening them is important, due to their adverse impact on growth and development.

The prevalence rate of thyroid function abnormalities was higher in females $(12.05 \%)$ than males $(5.36 \%)$. Thyroid function abnormalities were more prevalent in adolescents $(10.89 \%)$ than children $(7.82 \%)$ (Table 3$)$.

Subclinical hypothyroidism: The $\mathrm{SCH}$ was the most common $(4.08 \%)$ of the thyroid function abnormalities in our study; the prevalence was higher in females (Table 2); female: male ratio of 2.5:1. One of previous study had reported the of $\mathrm{SCH}$ as $6.1 \%$. [9]. The prevalence rate of $\mathrm{SCH}$ was higher in the adolescents than children (Table 3). The adolescent females were the most affected off all with a prevalence rate of $7.39 \%$ and female: male ratio of 5.67:1 (Table $4 \& 5$ ). The previous reported prevalence of $\mathrm{SCH}$ in children and adolescence is up to $2 \%$. $[4,5,11]$. The subjects with $\mathrm{SCH}$ need long term follow due to their unpredictable course, with 1 to $20 \%$ developing $\mathrm{OH}$ or hyperthyroidism during follow-up $[4,5,6,11]$.

Overt Hypothyroidism: The $\mathrm{OH}$ was the second commonest $(3.05 \%)$ of the thyroid function abnormalities (Table 2); however, a lesser prevalence rate $(0.4 \%)$ was reported in an earlier study [9]. The $\mathrm{OH}$ was more common in females than males; with female: male ratio of 2.43:1. (Table 2). Majority of cases $\mathrm{OH}$ were of primary hypothyroidism. (Table 2) The prevalence rate of hypothyroidism was higher in children than adolescents.

Hyperthyroidism: The hyperthyroidism was the third common disorder affecting $2.04 \%$ of subjects; which was also more prevalent in females; female to male ratio of $7: 1$ (Table 2). The prevalence rate of hyperthyroidism was higher in adolescents than children $\quad(2.29$ vs $1.84 \%) \quad$ (Table 3). The hyperthyroidism was more common in females than 
males in both children and adolescents age groups (Table $4 \& 5$ ). The prevalence of hyperthyroidism is known to increase during childhood and peaks during adolescence, and more common in females than in males, in a ratio of $3: 1$ to $5: 1$; consistent with observation of our study [7].

To summarize the present study is to first of its kind to assess the prevalence of thyroid disorders in children and adolescents with majority consuming iodized salt.

Limitations: Our study has few limitations; firstly, study sample was relatively smaller; however, post hoc power of our study is $90.7 \%$, which shows that sample size is adequate. Secondly, classification was based on kit manufacturers recommendations regarding normal values of TFTs, as there were no reference values for the study population.

\section{Conclusions}

The present study was the first of kind to assess the prevalence of thyroid function abnormalities in children and adolescents from northern Kerala.

Thyroid function disorders are common in children and adolescents; affecting about $\sim 9 \%$ in study population, underlining the importance of multicentre trials to assess their prevalence at national level; due to their adverse impact on growth and development. Thyroid function abnormalities were more common in females than males. The prevalence rate TFTs abnormalities was more in adolescents than children.

Subclinical hypothyroidism was the commonest thyroid disorder with a female to male ratio of $2.5: 1$; and the prevalence was higher in the adolescents than children. The subjects with $\mathrm{SCH}$ need long term follow due to their previously reported unpredictable course.

The $\mathrm{OH}$ was the second commonest of the thyroid function abnormalities; with female: male ratio of $2.43: 1$. Majority of cases $\mathrm{OH}$ were of primary hypothyroidism.

The hyperthyroidism was the third common disorder also more common in females; female to male ratio of $7: 1$. The prevalence rate of hyperthyroidism was higher in adolescents than children.

\section{References}

1. Alphonsus NO, Philip OA, Louis CO. Thyroid disorders in childhood and adolescence: a retrospective assessment of clinical data in a Nigerian teaching hospital. Pacific Journal of Medical Sciences 2012; 10: 3-11.

2. Alphonsus NO, Philip OA, Louis CO. Thyroid Disorders in Childhood and Adolescence: Analysis of Clinical Data and Management Challenges in Patients Seen in a Nigerian Teaching Hospital. Greener Journal of Medical Sciences. 2010; 2: 45-50.

3. Marvin L R, Brown M D, Wayne A M, Mary B, Joseph L L, Walter S. Natural history of thyroid abnormalities: Prevalence, incidence, and regression of thyroid diseases in adolescents and young adults. The American Journal of Medicine. 1991; 91 (4):363-370. DOI: http://dx.doi.org/10.1016/0002-9343(91)90153-O

4. Krishna GS. Subclinical hypothyroidism in children. Indian J Endocrinol Metab. 2012; 16 (8): 156-158. DOI: $10.4103 / 2230-8210.104028$.

5. Monzani A, Prodam F, Rapa A, Moia S, Agarla V, Bellone S, Bona G. Endocrine disorders in childhood and adolescence. Natural history of subclinical hypothyroidism in children and adolescents and potential effects of replacement therapy: a review. Eur J Endocrinol. 2012 Dec 10;168(1):R1-R11. doi: 10.1530/EJE-12-0656. Print 2013 Jan.

6. Counts D, Varma SK. Hypothyroidism in children. Pediatr Rev. 2009 Jul;30(7):251-8. doi: 10.1542/pir.30$7-251$.

7. Markus B. Thyroid disorders in children from birth to adolescence. European Journal of Nuclear Medicine 2002; 29 (S2): S339-S446.DOI 10.1007/s00259-0020905-3.

8. Rosalind SB. Thyroid Disease in Infancy, Childhood, and Adolescence in Contemporary Endocrinology: Diseases of the Thyroid. L. E. Braverman Humana Press Inc., Totowa, NJ.

9. Marwaha RK, Tandon N, Garg MK, Desai A, Kanwar R, Sastry A, Narang A, Arora S, Bhadra K. Thyroid status two decades after salt iodization: country -wide data in school children from India.

Clin Endocrinol (Oxf). 2012 Jun;76 (6):905-10. doi: 10.1111/j.1365-2265.2011.04307.x.

10. Marwaha RK, Tandon N, Desai AK, Kanwar R, Aggarwal R, Sastry A, Singh S, Narang A, Ganguly SK, Mani K. Reference range of thyroid hormones in 
healthy school-age children: country-wide data from India. Clin Biochem. 2010 Jan;43(1-2):51-6. doi: 10.1016/j.clinbiochem.2009.03.001. Epub 2009 Mar 11.

11. Shriraam M, Sridhar M. Subclinical hypothyroidism in children. Indian Pediatr. 2014 Nov;51(11):889-95.
12. Usha Menon V, Sundaram KR, Unnikrishnan AG, Jayakumar RV, Nair V, Kumar H. High prevalence of undetected thyroid disorders in an iodine sufficient adult south Indian population. J Indian Med Assoc. 2009 Feb;107(2):72-7.

\section{How to cite this article?}

Lakshminarayana Gopaliah $\mathrm{R}^{1}$, Sheetal Lakshminarayana $\mathrm{G}^{2}$, Nidhish P Sadanandan ${ }^{3}$, Pramod Mundekkat. Thyroid dysfunction in children and adolescence: Experience of a tertiary care centre in Kerala. Pediatr Rev: Int J Pediatr Res 2016;3(1):3-8.doi:10.17511/ijpr.2016.i01.02 